\title{
Not just another researcher
}

To the editor-Regarding "New NCI director appointed" (Nature Med. 8, 7; 2002), we write to observe that your News story has employed not-so-subtle, tiresome innuendo typical of the liberal establishment in this piece. For example, the caption under the photo reads, "Friend of Bush, Andrew von Eschenbach." And in the text, "Von Eschenbach was largely unknown to the biomedical research community..." On what sampling of this community do you base this statement? The fact that he leads a major program at one of the most distinguished cancer centers in the United States and is presidentelect of the American Cancer Society suggests that he is well respected in the world of oncology.

The story also says, "He replaces Richard Klausner who was widely regarded as a visionary leader... Whereas Klausner's career has included basic research, von Eschenbach has no background in basic research." We would argue that the National Institutes of Health (NIH), including the National Cancer Institutes, has had a sadly unbalanced portfolio grossly favoring bench research over clinically directed studies. For all of the hundreds billions of dollars plowed into the NIH during the last four decades, American citizens have seen scant returns (from NIH work) in the realm of public health. Thus, it seems timely and appropriate that an individual who is primarily focused on clinical issues should assume a leadership role in this vital institution.
We find the pattern reflected in the aforementioned piece banal and achingly politically correct.

\section{MiChael D. IsEMAN $^{1} \&$ ThOMAS L. PETTY $^{2}$ \\ ${ }^{1}$ Department of Medicine and Infectious Diseases University of Colorado School of Medicine \\ ${ }^{2}$ Division of Pulmonary and Critical \\ Care Medicine \\ University of Colorado School of Medicine \\ Denver, Colorado, USA}

We reply-Andrew von Eschenbach has been closely associated with the Bush family for a number of years. He has worked with President George W. Bush and first lady Laura Bush on the National Dialogue on Cancer (a national forum and public-private partnership devoted to setting a national agenda on cancer), and George H.W. Bush and his wife Barbara Bush are long-standing supporters of the M.D. Anderson Cancer Center, where von Eschenbach was formerly employed.

Our statement that von Eschenbach was hitherto largely unknown to the biomedical research community was based on discussions with several investigators from the international research community that comprises our biomedical research readership, and included scientists at the NCI itself.

Examination of von Eschenbach's extensive (180 citations) publication record confirms that his research interests center around more clinically focused cancer studies. As our journal targets scientists using more 'basic' approaches to the understanding of human disease, this discrepancy perhaps explains why those we contacted-scientists focused on the translation of basic research to the clinic, and not exclusively on clinical cancer treatment-were not familiar with von Eschenbach.

Undeniably, the lion's share of the NIH budget is spent on basic research, but we do not agree that this division is "sadly unbalanced," because the need to understand science at the basic level underpins its successful translation to the clinic. Furthermore, the NIH, via the NCI, in fact dominates clinical cancer research in the US: of the 1,444 active clinical trials, 1,127-involving 20,000 patients-are sponsored or conducted by the NCI.

Finally, we must disagree with your assertion that the American public has been short-changed by the NIH. The NCI has played an active role in the development of drugs for cancer treatment for over 40 years. This is reflected in the fact that approximately one-half of the chemotherapeutic drugs currently used by oncologists for cancer treatment were discovered and/or developed at NCI. Moreover, the incidence rate for all cancers has declined on average 1.1 percent per year between 1992 and 1998, and cancer death rates have fallen 1.6 percent per year for men and 0.8 percent per year for women between 1992 to 1998 . To say that the NIH has played no role in this trend would seem to be denying the facts.

We want to hear from you! Nature Medicine is the forum for the latest, best, and most original biomedical research, news, and opinion. As such, we welcome letters from readers wishing to address topics reported on in previous issues, or subjects of interest to the biomedical research community at large. Letters should be brief and concise (no more than $\mathbf{5 0 0}$ words), and sent to Nature Medicine, $\mathbf{3 4 5}$ Park Avenue South, New York NY 10010, USA, or sent by fax (212.683.5751) or email to medicine@natureny.com. 